\title{
Phytopathology
}

\section{Human Pathogens on Plants: Designing a Multidisciplinary Strategy for Research}

\author{
Jacqueline Fletcher, Jan E. Leach, Kellye Eversole, and Robert Tauxe
}

First author: National Institute for Microbial Forensics \& Food and Agricultural Biosecurity, Department of Entomology \& Plant Pathology, Oklahoma State University, Stillwater, OK; second author: Bioagricultural Sciences and Pest Management, Colorado State University, Ft. Collins, CO; third author: Eversole Associates, Bethesda, MD; and fourth author: Centers for Disease Control \& Prevention, Atlanta, GA. Accepted for publication 29 January 2013.

\begin{abstract}
Fletcher, J., Leach, J. E., Eversole, K., and Tauxe, R. 2013. Human pathogens on plants: Designing a multidisciplinary strategy for research. Phytopathology 103:306-315.

Recent efforts to address concerns about microbial contamination of food plants and resulting foodborne illness have prompted new collaboration and interactions between the scientific communities of plant pathology and food safety. This article provides perspectives from scientists of both disciplines and presents selected research results and concepts that highlight existing and possible future synergisms for audiences of both disciplines. Plant pathology is a complex discipline that encompasses studies of the dissemination, colonization, and infection of plants by microbes such as bacteria, viruses, fungi, and oomycetes. Plant pathologists study plant diseases as well as host plant defense responses and disease management strategies with the goal of minimizing disease occurrences and impacts. Repeated outbreaks of human illness attributed to the contamination of fresh produce, nuts and seeds, and other plant-derived foods by human enteric pathogens such as Shiga toxin-producing Escherichia coli and Salmonella spp. have led some plant pathologists to broaden the application of their science in the past two decades, to address problems of human pathogens on plants (HPOPs). Food microbiology, which began with the study of microbes that spoil foods and those that are critical to produce food, now also focuses study on how foods become contaminated with pathogens and how this can be controlled or prevented. Thus, at the same time, public health researchers and food microbiologists have become more concerned about plant-microbe interactions before and after harvest. New collaborations are forming between members of the plant pathology and food safety communities, leading to enhanced research capacity and greater understanding of the issues for which research is needed. The two communities use somewhat different vocabularies and conceptual models. For example, traditional plant pathology concepts such as the disease triangle and the disease cycle can help to define cross-over issues that pertain also to HPOP research, and can suggest logical strategies for minimizing the risk of microbial contamination. Continued interactions and communication among these two disciplinary communities is essential and can be achieved by the creation of an interdisciplinary research coordination network. We hope that this article, an introduction to the multidisciplinary HPOP arena, will be useful to researchers in many related fields.
\end{abstract}

Fruits and vegetables, often eaten without cooking, are important in a healthy diet, but they also are implicated increasingly in outbreaks of foodborne illnesses (54); annual public health outbreak surveillance has revealed increases in both numbers and sizes of disease outbreaks over the past several decades (77). The produce items most often identified in these outbreaks were leafy greens, melons, sprouts, berries, tomatoes, and green onions, all of which are likely to be eaten with minimal further processing. Outbreaks of Shiga toxin-producing Escherichia coli O157:H7 infection linked to lettuce and spinach $(38,87)$; salmonellosis

Corresponding author: J. Fletcher; E-mail address: jacqueline.fletcher@okstate.edu

http://dx.doi.org/10.1094/PHYTO-09-12-0236-IA

(c) 2013 The American Phytopathological Society linked to cantaloupes, tomatoes, and hot peppers $(10,14,33,60)$; hepatitis A linked to green onions (88); the Shiga toxin-producing E. coli $\mathrm{O} 104$ infections in Germany linked to fenugreek seed sprouts; and Listeria monocytogenes infections linked to cantaloupe (17) underline the challenge of fresh produce contamination (see

Note: Recent efforts to address concerns about microbial contamination of food plants and resulting foodborne illness have prompted new collaboration and interactions between the scientific communities of plant pathology and food safety. This article provides perspectives from scientists of both disciplines, and presents selected research results and concepts that highlight existing and possible future synergisms for audiences of both disciplines. 
Glossary for definitions of terms in bold font) occurring in the field or early in the processing phase. Enteric bacterial pathogens, commonly transmitted through foods, like Salmonella, Shiga toxin-producing E. coli, Shigella, and Campylobacter, are well adapted to vertebrate hosts and typically colonize the gut. Some have humans as their primary or sole host, while many others are sustained in animal populations, are adapted to a particular reservoir or environment, and affect humans only incidentally. For example, members of the genus Campylobacter are adapted to birds, in which they are commensal intestinal flora, and can transfer to poultry meat at slaughter (85). Some strains colonize cattle and are transmitted via raw cows' milk. Shiga toxin-producing $E$. coli $\mathrm{O} 157: \mathrm{H} 7$ can colonize the peri-rectal glands of ruminants and transfer from hides and feces to meat during the slaughter process (34). Salmonella enterica serotype Enteritidis can leave the gut to colonize the peri-ovarian tissues of a hen's reproductive tract, thereby contaminating the internal contents of normal appearing eggs (53). The phrase "human pathogens on plants" (HPOPs) has been proposed recently to describe such pathogens when they inhabit, colonize, enter, or otherwise interact with plants.

Interestingly, the Gram negative bacterial family Enterobacteriaceae, which includes many of the human pathogens associated with plant foods (e.g., Escherichia, Salmonella, and Shigella), also contains a number of genera of plant pathogens (Enterobacter, Erwinia, Pantoea, Pectobacterium, etc.) that cause plant diseases such as blights, wilts, and soft rots. The taxonomic relatedness of these plant and human pathogens raises interesting questions about the possibilities for niche competition or synergism, horizontal nucleic acid exchange in protected plant niches, or even host range expansion. There are microbial species, sometimes referred to as cross-over pathogens, that infect and cause disease on both plants and humans, though these are relatively uncommon. Examples of currently recognized cross-kingdom pathogens include a few bacterial species that commonly inhabit plant surfaces and the rhizosphere, such as Pseudomonas aeruginosa, Burkholderia cepacia, Dickeya spp., Enterococcus faecalis, and Serratia marcescens (84).

The plant disease triangle. A central dogma of plant pathology known as the disease triangle (Fig. 1) maintains that the development of a plant disease requires at least three components: (i) the pathogenic microbe must be virulent on a particular species and cultivar of plant; (ii) the plant host must be susceptible to a particular strain/isolate/biotype of a pathogen; and (iii) environmental conditions including temperature, humidity, and availability of nutrients for the pathogen must be suitable for both pathogen survival and the interactions that lead to disease. In cases in which an insect vector is required for pathogen dissemination, some plant pathologists have expanded the concept to that of a disease pyramid with the fourth dimension representing the insect (this fourth dimension would encompass any other type of living vector as well). Venn representations of these concepts (Fig. 1) emphasize that without all three (or four) components disease will not occur.

The plant disease cycle. A second dogma of plant pathology is that, although every disease is unique, for a given plant disease the pathogen, plant, and environment (and insect vector, if involved) interact with one another in generally predictable ways that can be represented as a disease cycle. The disease cycle is a holistic picture that summarizes the process within the context of an environment that includes both natural systems and agricultural inputs. Critical nodes include pathogen overwintering/overseasoning, dissemination/ transmission mechanisms, inoculation, colonization (multiplication), infection and establishment, disease initiation, symptom development, and pathogen propagule formation finally closing the cycle. Relevant subcycles and alternative pathways are often incorporated.
The disease cycle is far more than a device by which to remember the steps of the disease process, however. Logic tells us that disease may be hampered or prevented by blocking any step in the cycle. Thus, each cycle node or pathway is an opportunity for disease management and a potentially fruitful area for research into best management practices. For example, the plant pathogenic bacterium Xanthomonas axonopodis pathovar (pv.) vesicatoria spends much of its life as an ephiphyte on the surfaces of a variety of plants, living on plant exudates, interacting with other members of the phylloplane microbial community, and forming colonies protected and facilitated by biofilm formation (Fig. 2). Only on certain plants in the family Solanaceae, such as tomatoes and peppers, and only when conditions remain suitably warm and humid for several days do some bacteria enter the plant through natural openings such as stomata or through wounds. Their internal colonization leads to infection and to the physiological processes that result in the disease known as bacterial spot, and to the appearance of characteristic necrotic spot symptoms on leaves and fruits (Fig. 2; 68).

Affected leaves often abscise and accumulations of bacterialaden plant debris and seeds provide inoculum for subsequent infections. The impact of this disease can be economically devastating with some growers even plowing under their crops if disease begins early in the season when a minimal yield appears certain. The bacterial spot disease cycle (Fig. 2; 68) shows not only the steps of disease progression but also that disease development can be interrupted by strategies that target various nodes. Although the cycle could begin at any point, for the sake of simplicity we begin our example with seed contamination (\#1 in Fig. 2), where a farmer could kill bacteria in contaminated seeds by applying heat or chemical treatments during storage or before planting. Other strategies to limit damage take advantage of different weak points in the cycle, including (\#2 in Fig. 2) removing potentially infected crop debris from the field after harvest, (\#3) targeting the epiphytic phase of the life cycle, (\#4) preventing

\section{GLOSSARY}

Abscise: detach, as a senescing leaf from a stem

Colonization: multiply and establish a physiologic relationship with a host; may or may not lead to disease

Contamination: presence of undesirable organisms

Enteric: associated with the animal gut

Epiphyte: resident on a plant surface

Endophyte: resident within a plant

HPOP: a human pathogen that can be found in association with plants

Hydathode: natural plant pore, located at leaf tips and edges, through which gas exchange and water loss occurs

Infect: establish a physiological relationship with a host leading to disease

Infest: be present on or in

Pathovar (pv.): informal plant-pathogenic bacterium taxon defined by the plant host range

Phylloplane: the surface of a plant

Propagule: a pathogen life stage, usually asexual, that is dispersed

Rhizosphere: the region proximal to a plant's roots

Serotype: pathogen type defined by serological reactions to surface antigens

Stomate/stomata: natural plant pores, on leaf, flower and stem surfaces, through which gas exchange and water loss occurs; openings regulated by the turgor pressure of guard cells

Trichome: hair-like projection of a leaf epidermal cell 
aerial pathogen dispersal, or (\#5) treating plants with bactericide sprays, either at the time of symptom appearance or on a regular spray schedule during periods when the plant is susceptible and weather conditions are conducive to disease development.

The involvement of arthropods and other animals (birds, wild mammals, reptiles, etc.) as vectors of a number of plant pathogens, the ample evidence that a variety of insect species move freely between livestock holdings and produce fields, and the many reports of human pathogens carried on insect mouthparts, legs, and wings suggests that studies of HPOP dissemination within the environment would be incomplete without consideration of the myriad of species that commonly move back and forth between these agricultural settings $(15,23,55,80)$. Indeed, laboratory experiments have shown that blow flies can pick up E. coli O157:H7 from contaminated manure and deposit them onto the phylloplane of a number of edible plant species, where the bacteria can then colonize and multiply (80). Whether this happens in nature on a significant level remains unclear.

Can a holistic diagram such as the plant disease cycle be useful for managing foodborne human pathogens too? Several authors have represented HPOP-plant interactions and associated factors $(9,15,82)$ in diagrams reminiscent of a disease cycle, and these do, in fact, suggest a variety of points for interrupting the process or reducing human pathogen amplification.

Disease management-plant-pathogenic bacteria. Numerous plant disease management strategies that are not obvious from the disease cycle also could be useful when applied to HPOPs. Cultural practices, such as providing well-drained soils, avoiding low, frost-prone or water-logged areas, and applying fertilizers well-matched to a crop species, promote healthy, robust plant growth and plant defense responses. Identifying and treating pathogen reservoirs such as contaminated water, soil, or equipment helps eliminate or reduce inoculum the next season. Insects that can disseminate bacteria and also cause wounds through which bacteria enter can be controlled through integrated pest management (IPM) strategies, including judicious application of appropriately labeled antimicrobials. While partial control of some plant diseases can be achieved with biological control (i.e., the use of benign microbes to occupy plant niches that would otherwise be available to pathogens, to secrete bacteriocins, or to out-compete harmful ones for scarce nutritional resources), more effective biocontrol agents are needed. Finally, we now have plant cultivars that are resistant to certain plant pathogens. Although complete immunity is an unreasonable goal, increased resistance can help keep plant disease levels below an economic threshold. Can some of these same strategies work also for HPOPs?

Understanding interactions reveals clues for control. Most of our knowledge of plant-microbe interactions is built on studies involving plant interactions with plant pathogenic or beneficial microbes $(48,51,52,72)$. Communications between the plant and the microbe can occur on the plant surface (epiphytes on leaves, roots, fruits, or stems) or within the plant (endophytes that colonize between plant cells or in the vascular system). In other words, the plant senses the pathogens' presence, and this recognition can determine whether the microbe can successfully colonize the plant or whether the plant mounts a defensive response and thwarts infection. Recent research, stimulated in part by human disease outbreaks attributed to plant based foods (nine research projects were funded in 2007 by a fresh produce company to address practical questions and find practical solutions to microbial contamination of fresh produce [63]) has shown that human enteric pathogens also can have complicated interactions with plants.

HPOPs are usually thought of as having a reservoir in the intestines of a vertebrate host and, once shed in manure, can come into direct or indirect contact with produce by various routes. Thus, historically, they were considered to be transient on plant surfaces, persisting passively in cracks, wounds, and natural openings such as stomata or hydathodes (respiratory pores on plant surfaces or edges, respectively). They were thought incapable of actively modifying the plant or communicating with it. However, it is now clear that enteric bacteria don't just "land" on and passively inhabit plants. These pathogens can adhere tightly to produce, multiply, and enter into the tissues of leaves or fruits, in some cases even moving into other plant parts $(12,24)$. Since washing food surfaces can remove only part of this contamination (13), it is particularly important to understand and prevent contamination from happening in the first place $(9,62,70,73)$.

For example, E. coli O157:H7 or Salmonella spp. that contaminate alfalfa seeds will multiply rapidly in the young sprouts, appearing at high counts throughout the young plant $(24,53)$. Salmonella spp. splashed onto leaves may enter them and spread via the plant's vascular system to other edible parts of the plant (12). Human enteric pathogens have been shown to enter warm fruits placed in cold water because of internal pressure changes $(30,43,44)$ and to enter edible plant tissues through bruises and wounds $(64,71)$. There are recurrent associations between particular pathogens and particular produce types, e.g., pathogenic $E$. coli is more often associated with leafy greens, while Salmonella $\mathrm{sp}$. is more often associated with tomatoes and cantaloupes. Is this simply the result of contamination geography and opportunity or is a more specific specialization present? Once on a plant, bacteria demonstrate preference for certain niches; on tomato leaves, S. enterica prefers the shelter of type I trichomes on leaf surfaces (6). In contrast, on fresh lettuce leaves in the dark Salmonella cells distribute randomly over the leaf surface, but when light stimulates photosynthesis, they concentrate at the stomatal openings (respiratory pores) on the leaf, possibly drawn

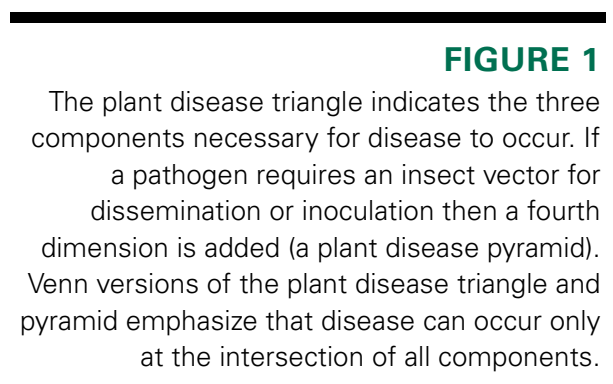

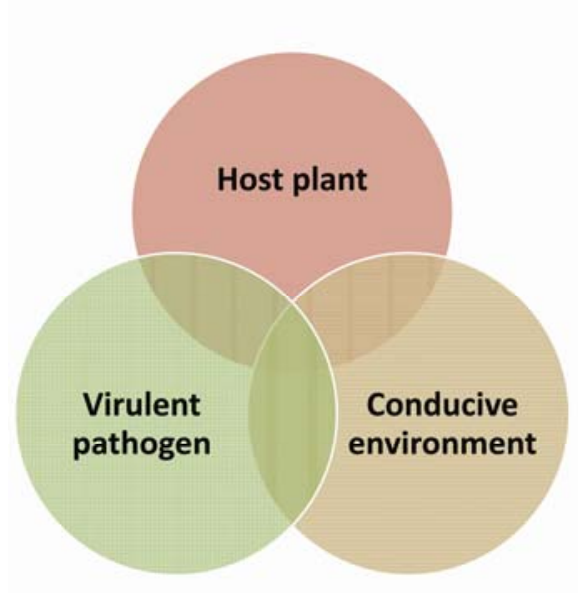

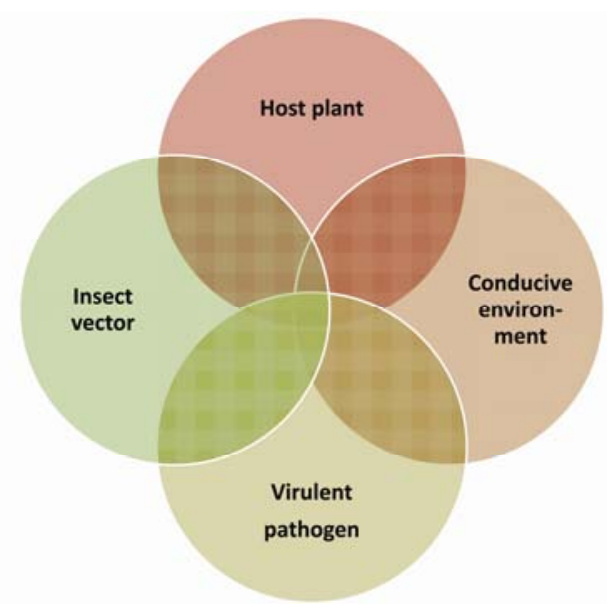


to products of photosynthetic metabolism (47). Some HPOPs, like some phytopathogenic bacteria, even manipulate the opening or closing of those stomatal pores by signaling the encircling guard cells, whose turgor pressure changes control the pore size (16, $47,57,58,72,91)$. One research group reported that E. coli $\mathrm{O} 157$ uses a specific type III secretion system effector to manipulate the stomatal guard cells of spinach leaves so that they open (72). Human bacterial pathogens may even spread within a plant during the reproductive process, as Salmonella spp. placed on the pistil of a tomato or cantaloupe flower can travel to the ovule and colonize new fruits as they form there $(28,32)$. Many of these interactions mimic those of other microbes that have nothing to do with human illness, but which are well studied by plant pathologists. The field of plant pathology thus has important contributions to make in understanding the factors involved in microbial contamination of plant based foods and improving strategies for minimizing that risk.

As a result of these and other findings, a working hypothesis emerging among food scientists and plant pathologists is that adaptation to persist and grow on plants and associated environments (soil, rhizosphere, etc.) is a natural part of the life cycle for human pathogens just as it is for plant-pathogenic microbes (73, 82). Like plant pathogens, human pathogens can persist in soil and in crops for prolonged periods $(7,41,42,45,89,90)$. Some human pathogens, such as Salmonella spp. and E. coli O157, not only associate with and colonize plant surfaces, but more alarm- ing from a food safety perspective, they internalize within the structure of the plant, though not necessarily within the plants cells, and live as endophytes within the plants (21). Even more surprising to the research community was evidence that human pathogens actively communicate with plants and other plantassociated microbes during the plant/environment part of their life cycle (40,73-75). Knowing how human pathogens interact with plants and what these processes share in common with plant pathogens provides clues for actively managing HPOPs.

HPOPs and plant pathogens share lifestyle strategies. When it comes to the genes that are required for survival in the environment and for interactions with eukaryotic hosts, microbes, regardless of whether they are adapted to human or plant hosts, share many genetic mechanisms. Since human pathogens attach to, multiply in and colonize plants, and exhibit preferences for tissues, commonalities with plant pathogens in the mechanisms they use for colonization of plants would be expected. The nature of the particular phylloplane environment encountered by any microbe is a critical element in whether that organism will perish, survive, or thrive there. The availability of water and nutrients is essential for colonization and may also contribute to host specialization. Nutrients are supplied in the form of natural plant exudates, fluids that leak from wounded plant surfaces or broken trichomes, insect feces (honeydew), and decaying organic matter $(2,83)$. If a film of water is present, plant pathogens may display chemotaxis, translocating by means of flagella toward attractive substances or away

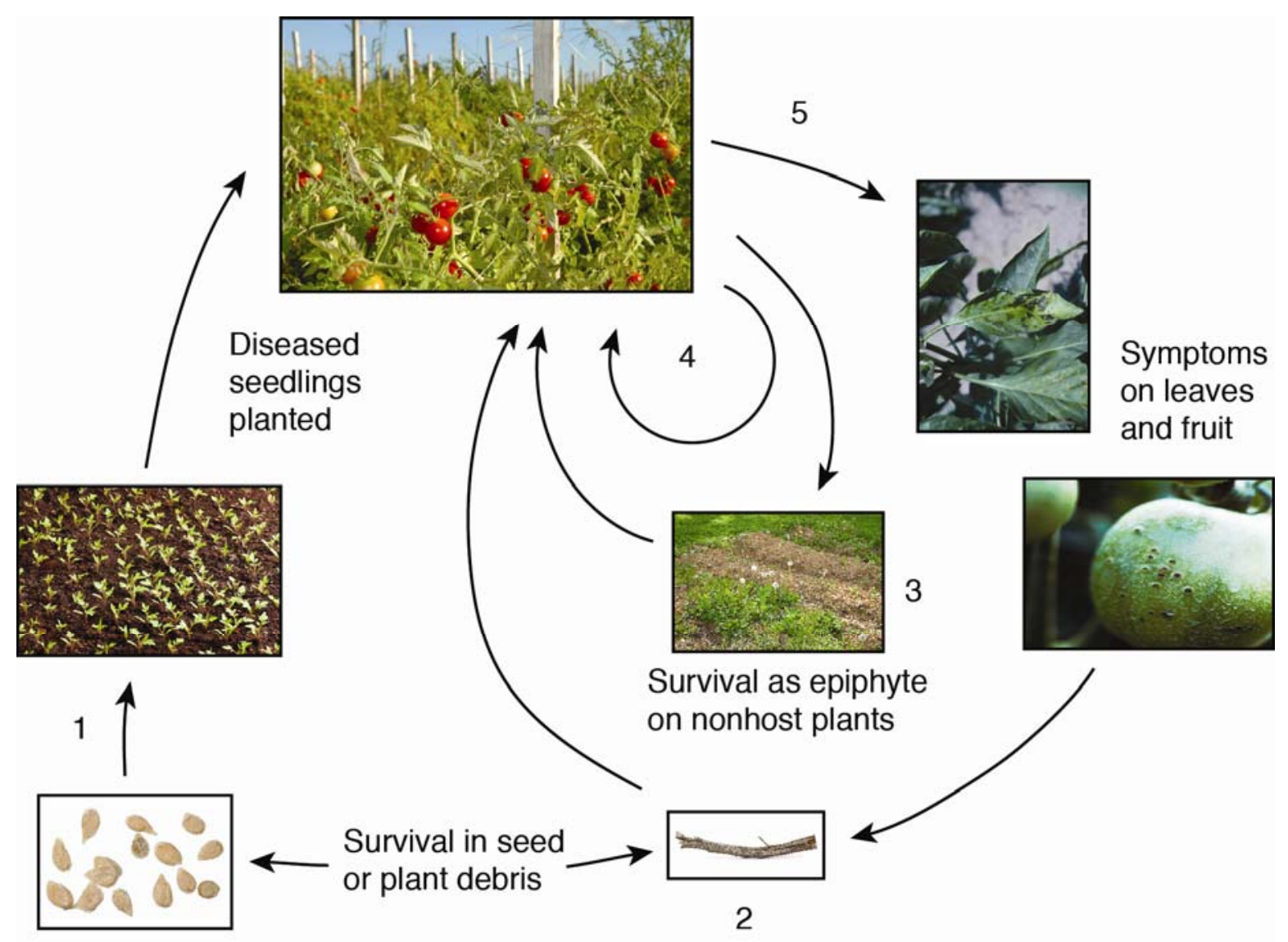

\section{FIGURE 2}

Disease cycle of bacterial spot of pepper and tomato, caused by Xanthomonas axonopodis pv. vesicatoria. (Adapted, with permission, from Ritchie [68]. Images courtesy of Florida Division of Plant Industry Archive, Florida Department of Agriculture and Consumer Services, Bugwood.org (diseased leaves); Graves, A. S., and Alexander, S. A. 2002. Managing bacterial speck and spot of tomato with acibenzolar-S-methyl in Virginia. Online. Plant Health Progress doi:10.1094/PHP-2002-0220-01-RS [diseased tomato fruit]; Kawia Scharle/Shutterstock.com [tomato seeds]; Denis Nata/Shutterstock.com [tomato seedlings]; Jerry Horbert/Shutterstock.com [tomato plants]; J. Bicking/Shutterstock.com [nonhost plants]; and Farres/Shutterstock.com [twig]). 
from repellent ones. For example, Erwinia amylovora, the causal agent of fire blight of apples and pears, moves toward a variety of organic acids present on apple leaves (66).

Some genes that affect human pathogen virulence in vertebrates are also involved in their attachment to and colonization in plants, though not to cause plant disease $(4,5,72)$. Further, some Salmonella sp. genes, such as those encoding cellulose and O-antigen capsule seem to be related specifically to colonization of plants (and not necessarily of vertebrates) (5). An early described example of shared strategies was that both plant and human pathogens require type III secretion systems (TTSS) to cause disease. Not surprisingly, when whole genome comparisons among microbes became feasible, even more commonalities between human and plant pathogens microbes were revealed. The use of mutagenesis approaches to characterize the functions of common genes has shown repeatedly that many are involved in the production of virulence factors or are required for host invasion and colonization or adaption to environment-imposed stresses, and that these are essential for pathogenesis to both plants and humans $(4,5,74,79)$ Both groups of pathogens produce exopolysaccharides that can protect pathogens from desiccation as well as from host recognition; appendages such as flagella, pili, or in the case of some HPOPs, coiled, aggregative filaments known as curli (83), and fimbriae, all of which have roles in co-aggregation and adherence to host surfaces (81). Siderophores produced by both groups sequester elemental iron, an essential cofactor in many host functions (35). Both human and plant pathogens form biofilms, complex, often multispecies microbial communities that allow diversification of roles of individual community members and toxins $(3,35,49,50,67)$. While they may use different molecular languages for quorum sensing, there is evidence that human enteric bacteria can perceive signal molecules used by plant pathogens for regulation of pathogenicity genes (for review, see Roper [69] and Smith et al. [78]). As mentioned above, both use highly conserved secretion systems, such as TTSS, to deliver virulence factors to the host surface or inside the host cell $(73,74,79)$.

Bacteria that cause illness in both plants and vertebrates may have genes that contribute to the virulence in both hosts. For example, Pseudomonas aeruginosa is a particular problem for children with cystic fibrosis, in whom it causes persistent lung infections; it also can infect plants and other hosts. Isolates of $P$. aeruginosa obtained from ill humans studied by gene deletion showed two pathogenicity islands, both of which contained genes for plant and animal virulence. Remarkably, half of the genes studied contributed to virulence in both hosts (36). Using cross kingdom models may provide a way to screen for virulence factors. For example, strains of $P$. aeruginosa from cystic fibrosis patients were tested for their ability to invade a wounded alfalfa seedling. Invasiveness in young plants was associated with a gene controlling the production of alginate, a factor related to harmful persistence of certain strains in children with cystic fibrosis (76).

It is important to note that the common tools shared by human and plant pathogens are not used only for interactions or communications with their hosts. They are also critical components of their interactions with other microbes in the environment and within the tissues of either host. For example, biofilms, which are important in many cases for pathogenesis $(3,5,49)$ and protection of microbes, are frequently composed of multispecies communities $(20,26,27,61,67)$. Forming such a community would likely involve communications among the bacteria within the biofilms $(3,7)$. It has been speculated that colocalization of human and plant pathogens within biofilms or within plants may benefit the less adapted human pathogen $(3,7,86)$. In addition, colocalization of the microbes would provide opportunities for genetic exchange among the diverse pathogens; this possibility for transfer of genetic information is of concern, as traits that improve fitness of both types of pathogens (antibiotic resistance, etc.) may be exchanged. One example is the emergence of streptomycin-resistant strains of plant pathogens (Erwinia amylovora, Pseudomonas spp., and Xanthomonas campestris) and the observations that some of the streptomycin resistance genes in these bacteria are associated with transfer-proficient mobile elements, and that the genes are similar to streptomycin resistance genes found in bacteria isolated from humans, animals, and soil (for review, see Heuer et al. [37] and McManus et al. [56]). The fact that several important and widely occurring plant pathogens are members of the family Enterobacteriaceae, closely related to significant HPOPs, makes interspecies gene transfer even more likely.

Since plant pathogens and human pathogens use several common mechanisms for infection, colonization, and survival in the host, strategies that interfere with these processes, used for controlling plant pathogens, might also control HPOPs. One approach is to target the quorum sensing communication pathways used by the microbes. Several plant pathogenic members of the family Enterobacteriaceae, including those that colonize vascular and intercellular spaces, communicate using N-acyl-Lhomoserine lactones (AHLs) that bind to transcriptional regulators and activate or regulate target genes important for plant colonization (for review, see Crepin et al. [19] and Roper [69]). Human enteric pathogens, such as E. coli and S. enterica, do not synthesize AHLs, but they do contain an AHL receptor that can bind AHLs produced by other bacterial species and thereby use this quorum sensing signal to regulate their own gene transcription (for review, see Smith et al. [78]). By expressing an enzyme that hydrolyzes the lactone bond of AHLs in tobacco, Dong et al. (22) interfered with the inter-bacterial communications and significantly increased resistance of the tobacco to infection by the plant-pathogenic Enterobacterium Erwinia carotovora.

Plant genetic resistance. Plants are protected from potential pathogens by surface barriers (e.g., thick cell walls, waxy cuticle) or through the activation of innate immune responses (reviewed by Abramovitch et al. [1]). The latter are activated by the interaction of pathogen-associated molecular pattern (PAMP) molecules with plant extracellular plasma membrane receptors called pattern recognition receptors (PRRs) (reviewed by Ingle et al. [39]). PAMPs, such as flagellin, lipopolysaccharides, and chitin, are essential components of many microbes, including human and plant pathogens, regardless of their location. Detection of PAMPs by PRRs leads to the activation of a series of defensive responses that inhibit microbial multiplication and growth. These responses include production of reactive oxygen species (ROS), alkalinization of the spaces between plant cells, and cell wall reinforcement through deposition of callose and lignin (reviewed by Gimenez-Ibanez et al. [29]). Collectively, these responses are called PAMP-triggered immunity (PTI) (39). Successful plant pathogens have evolved the capacity to actively suppress PTI by translocating proteins called effectors into the plant cell using a TTSS (reviewed by Chisholm et al. [18]). As plants and pathogens co-evolved, plants developed the capacity to detect the pathogen-produced effectors and to activate stronger and faster defense responses. This process, called effector triggered immunity (ETI), is activated by plant resistance (R) proteins that 'recognize' and inhibit the activity of the effector proteins and, through activation of ETI, suppress microbial multiplication and spread. Fascinating recent studies suggest that human enterobacteria, such as $S$. enterica serovar Typhimurium, also have the capacity to actively suppress the plant PTI $(74,75)$. A TTSS mutant of Salmonella spp. was unable to suppress plant defense responses, suggesting that Salmonella spp. depend upon the TTSS during plant infection (65). Furthermore, Salmonella Typhimurium effectors, introduced into tobacco and Arabidopsis cells via Agrobacterium tumefaciens transformation or via the TTSS of the plant pathogen Xanthomonas campestris pv. vesicatoria trans- 
formed with the Salmonella Typhimurium effector genes, were able to suppress PTI responses $(74,75)$. These and other studies provide strong evidence that human pathogenic microbes communicate intimately with plant cells through the delivery of TTSS effectors, and that these effectors elicit and control plant responses (73-75).

It is important to remember that since human pathogens cause human illness merely by being physically present (and viable) in low numbers, a traditional definition of plant resistance to plant pathogens may not work as a functionally useful definition of plant resistance to human pathogens. Yet, if human pathogenic microbes do produce PAMPs and are able to control plant responses through injection of TTSS effectors, the implications would be profound. If plants have evolved resistance mechanisms that protect against HPOPs as well as plant pathogens, those pathways can be exploited to minimize HPOP establishment and colonization on and in plants. In fact, plant hosts that differentially respond to human pathogens already have been identified $(6,8,46,59,65)$. Different tomato cultivars vary in their abilities to support colonization by $S$. enterica, and these differences seem to be correlated with variation in the types of leaf trichomes present (6). E. coli $\mathrm{O} 157: \mathrm{H} 7$ colonization patterns on different spinach cultivars correlated with leaf surface topography (59). Knowing that plant host variation is associated with resistance or differences in ability to support human pathogen populations is the first step in identifying the correlated heritable traits, and integrating these into crop improvement strategies to reduce the risk of food contamination.

Hypothesis: A multihost cycle? The observation that some enteric bacteria are surprisingly well adapted to persistence on and in plants raises the question of whether these bacteria, and perhaps some viruses and parasites as well, that typically are assigned to a reservoir in the vertebrate gut, could persist in plants through plant life cycle stages and be present in leaves, fruits or seeds. Doing so may be an advantage to enteric bacteria whose vertebrate hosts are herbivores. Presence in the plants that the herbivores eat may represent a pathway to the next herbivore (Fig. 3). Enteric pathogens will be excreted from the herbivores' guts along with undigested seeds of the plants that the herbivore ate, seeds that will subsequently sprout and produce another generation of food plants. If the pathogens are either already within or attached to the seeds, enter the young plant and persist as the plant grows, then they again have the opportunity to be eaten by a passing herbivore. Transfer events from herbivore to plant and from plant to herbivore may be very frequent in the prairie or pasture. The omnivorous human may encounter the bacteria on either side of this more complex cycle, by eating either the herbivore or the plants bearing the pathogen. This scenario supports a previously proposed viewpoint that efforts to reduce the contamination of our food supply should be designed within a holistic framework, that includes the water, soil, and environments in which our food plants grow as well as to the more traditional concerns about safer water, fodder, and environments for our food animals (11).

Research priorities. Over the past decade we have learned much about the commonalities among and differences between HPOPs and plant pathogens, and this growing area of study informs a larger body of knowledge about foodborne pathogens and their management. Nonetheless, outbreaks have continued to occur, and we need to learn much more about the processes by which foodborne illness arises from the consumption of plantbased products. The continued challenge of outbreaks associated with fruits and vegetables led, in 1998, to the provision by the FDA of general industry guidance for minimizing food safety hazards (31), and in late 2010 the U.S. Congress passed the FDA Food Safety Modernization Act (Public Law 111-353), commonly referred to as FSMA. FSMA calls for a variety of science-based performance standards focused on major food contaminants. Significantly, FSMA expands the FDA's regulatory authority to the farm level and requires the FDA to establish new, sciencebased minimum performance standards for the production and harvesting of fruit and vegetables (Public Law 111-353; 21 United States Code 350h) (25). This proposed regulation, which was announced by the FDA on 4 January 2013, addresses water quality, wildlife incursion, worker sanitation, and other likely sources of contamination of fresh produce based on available scientific data (FDA, Docket No. FDA-2011-N-0921). As this regulation is put into final form and implemented, additional applied research questions are likely to arise.

To minimize foodborne illnesses associated with HPOPs and, at the same time, provide scientific information for improving onfarm production and harvesting standards, we will need to continue to support targeted rigorous research. It is important to gather more fundamental knowledge of the biology and genetic variability of HPOPs, over time and by commodity and location, the differences in farming practices and other governmental requirements (e.g., conservation or environmental requirements), and, most importantly, the interactions between the human pathogens, plant associated microbes, the host plant, and the environment. This is not a single simple system; there are issues specific to each fruit or vegetable cultivar, the location in which it is grown, and the practices associated with that location. Though

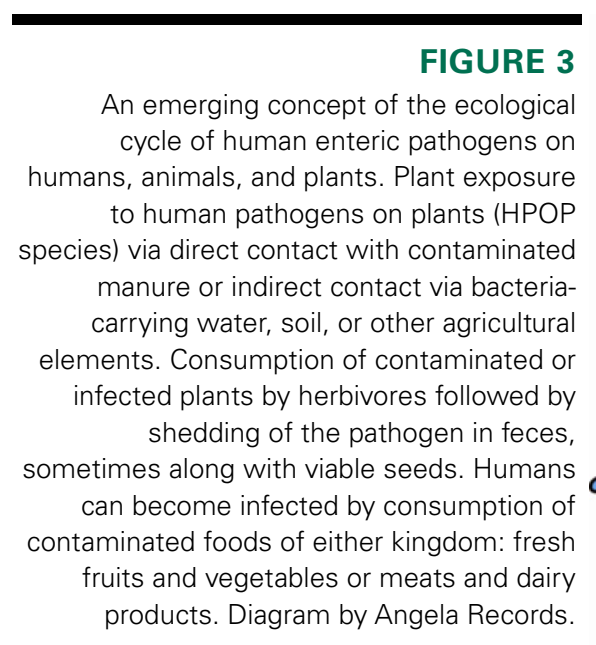

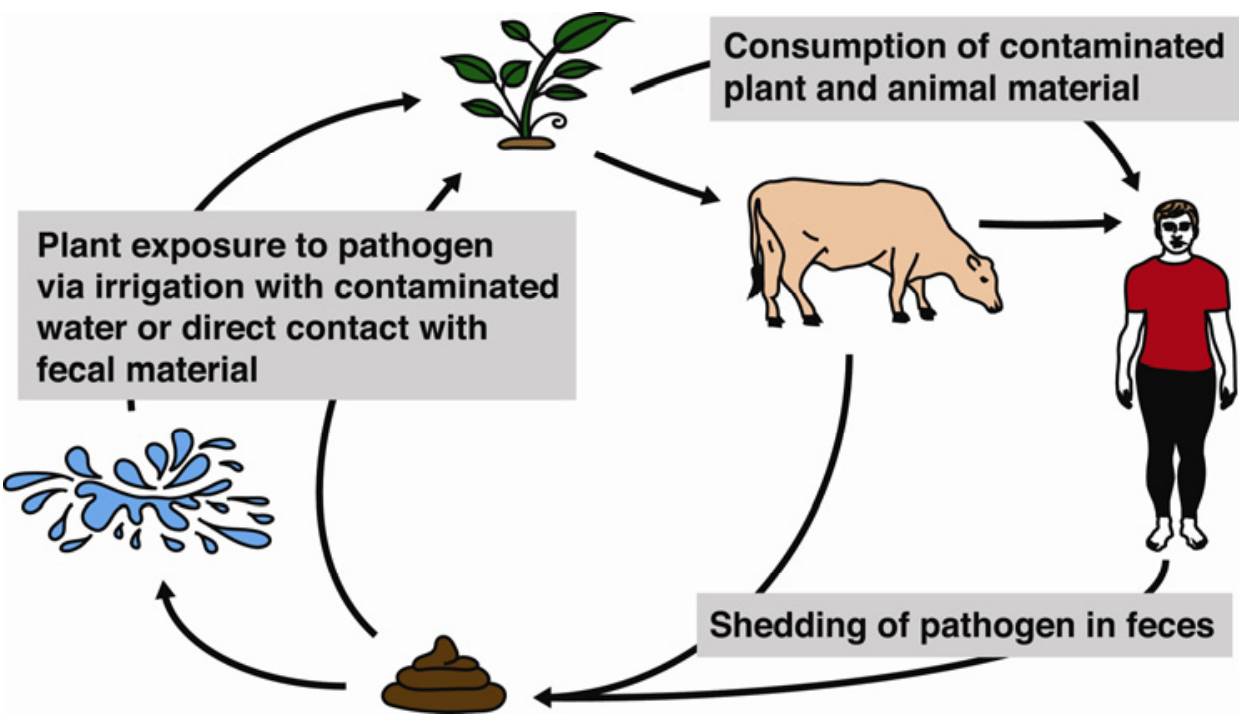

Vol. 103, No. 4, 2013 
most of the work to date has focused on bacterial pathogens, viral, protozoal and fungal pathogens also must be addressed. It will be helpful to apply a systems approach that recognizes and takes advantage of the full cycle. Addressing HPOPs from a disease cycle perspective brings a number of research questions to mind (Research Priority Boxes 1 to 5), including aspects of epidemiology, biology, control, surveillance, and ecology.

Next steps: Encouraging multidisciplinary research, extension, and education through an HPOP Research Coordination Network. Several years ago, The American Phytopathology Society's (APS) Public Policy Board (PPB) began to encourage more plant pathologists to become involved in efforts to reduce the risks of HPOPs and to explore opportunities to bring relevant disciplinary communities together. Plant pathology careers vary widely and include both fundamental and applied researchers, educators, and extension agents who work directly with growers and farmers. While a number of APS members already were engaged in advancing the science of HPOPs, it was clear that more could be done. Even plant pathologists who do not work with HPOPs may have unique, important perspectives that may be relevant as practical solutions are sought. Furthermore, plant pathologists will benefit from gaining an appreciation of approaches typically taken by food microbiologists and epidemiologists. Leaders from the APS PPB held workshops at the FDA and the U.S. Department of Agriculture that presented the basics of plant pathology from the disease cycle to extension. Encouraged to disseminate our message more broadly to the food safety

\section{Research Priorities: 1. The disease cycle}

- How often are HPOPs found on or in plants at point of harvest, or in seeds destined for production of edible sprouts?

- What are the most important pathways for HPOP contamination of plants? Are there as yet unrecognized vectors and hosts?

- What mechanisms do HPOPs use to colonize, persist, and thrive on plants?

- Are HPOP genes expressed differentially in different hosts/ tissues/niches?

- Are there elements in the phyllosphere or rhizosphere that encourage or discourage HPOPs?

- How do human pathogens interact with plant pathogens on plants?

\section{Research Priorities: 2. On the farm}

- How can we best communicate risk that may be low, but not zero?

- What can growers do to reduce risk?

- Are there farming practices that may influence the environment and make it easier or harder for HPOPs to persist?

- How can we develop standards that recognize the differences in practices, location, commodities, scope, and mitigation?

- How do we engage and learn from extension pathologists and crop consultants?

- How can we best communicate risk that may be low, but not zero? community, we held highly successful symposia at the annual meetings of both the International Association for Food Protection and APS, both of which brought in food microbiologists and epidemiologists. Enthusiastic audience participation at those workshops led to the establishment of the cross-disciplinary APS Food Safety Interest Group.

Most recently, to further enhance the relationship between our diverse professions, a multidisciplinary team with broad representation from both the plant pathology and food safety communities hosted a research workshop in College Park, MD, in February 2012 for active researchers and extension pathologists working on HPOPs. Goals of the meeting were to bring members of the disciplines together, exchange research strategies and findings, set research priorities for interdisciplinary cooperation, and develop a mechanism for continuing those interactions into the future. The event, which was funded by a conference grant from the U.S. Department of Agriculture AFRI Food Safety Program, attracted over 125 attendees. One highlight was the announcement by Editor-in-Chief George Sundin of the firstever Phytopathology focus issue, to highlight the expanding field of HPOP research.

To sustain the momentum and further encourage the food safety and plant pathology communities to work together to reduce the threat of HPOPs, we propose the establishment of a research coordination network $(\mathrm{RCN})$. While funding for developing a network may come from a variety of sources, the U.S. National Science Foundation (NSF) has supported several RCNs in the biological and engineering sciences in the past, including the APS supported RCN for U.S. culture collections. According to the NSF (www.nsf.gov), RCNs should advance a field or create new

\section{Research Priorities: 3. Management strategies}

- Are some plant cultivars more resistant to HPOPs than others?

- What active resistance mechanisms and natural inhibitors do plants use against HPOPs?

- Can we make plants more resistant to colonization by HPOPs?

- Can epiphytic phylloplane microbes trigger plant resistance to pathogens?

\section{Research Priorities: 4. Basic questions}

- Are (some) HPOPs pathogenic to plants?

- Can plant defense responses be harnessed to reduce HPOP risk?

- Do cross kingdom pathogens pose a risk to food safety?

- What additional HPOPs can be identified?

\section{Research Priorities: 5. Other research dilemmas}

- How can we establish effective strategies for detecting very low microbial populations in the field?

- What would an appropriate surrogate model look like?

- How can plant pathology principles be applied to human viruses (i.e., Norovirus, hepatitis A, etc.) on plants? 
directions in research and education. A successful NSF RCN would gain support for fostering collaborations (domestic and international) and multidisciplinary activities. An HPOP RCN can provide an opportunity for collaborations between extension educators and agents, growers, and scientists (plant pathologists, food microbiologists, and epidemiologists) in academia, government, and industry. It can serve to facilitate the development of multidisciplinary proposals aimed at addressing some of the fundamental and applied questions. It also may allow us to bring to the HPOPs field additional plant pathologists with expertise in understanding plant-microbe interactions and to prepare extension personnel to assist growers in understanding and compliance with new production and harvesting standards. Finally, an HPOP $\mathrm{RCN}$ will allow us to continue to expand our understanding of the entire HPOPs system-the full disease cycle.

\section{ACKNOWLEDGMENTS}

We thank A. Records for contributing the original artwork in Figure 3 and for adapting material from Ritchie (68) for Figure 2.

\section{LITERATURE CITED}

1. Abramovitch, R. B., Anderson, J. C., and Martin, G. B. 2006. Bacterial elicitation and evasion of plant innate immunity. Nat. Rev. Mol. Cell. Biol. 7:601-611.

2. Aruscavage, D., Phelan, P. L., Lee, K., and LeJeune, J. T. 2010. Impact of changes in sugar exudate created by biological damage to tomato plants on the persistence of Escherichia coli O157:H7. J. Food Sci. 75:187-192.

3. Barak, J. 2004. Biofilms and other strategies exploited by salmonella and friends on plants. (Abstr.) Phytopathology 94(suppl.):S128.

4. Barak, J. D., Gorski, L., Naraghi-Arani, P., and Charkowski, A. O. 2005. Salmonella enterica virulence genes are required for bacterial attachment to plant tissue. Appl. Environ. Microbiol. 71(10):5685-5691. doi:10.1128/ Aem.71.10.5685-5691.2005

5. Barak, J. D., Jahn, C. E., Gibson, D. L., and Charkowski, A. O. 2007. The role of cellulose and O-antigen capsule in the colonization of plants by Salmonella enterica. Mol. Plant-Microbe Interact. 20:1083-1091. doi: 10.1094/mpmi-20-9-1083

6. Barak, J. D., Kramer, L. C., and Hao, L. Y. 2011. Colonization of tomato plants by Salmonella enterica is cultivar dependent, and type 1 trichomes are preferred colonization sites. Appl. Environ. Microbiol. 77(2):498-504. doi:10.1128/AEM.01661-10

7. Barak, J. D., and Liang, A. S. 2008. Role of soil, crop debris, and a plant pathogen in Salmonella enterica contamination of tomato plants. PLoS One 3(2). doi:10.1371/Journal.Pone.0001657

8. Barak, J. D., Liang, A., and Narm, K. E. 2008. Differential attachment to and subsequent contamination of agricultural crops by Salmonella enterica. Appl. Environ. Microbiol. 74(17):5568-5570. doi:10.1128/ Aem.01077-08

9. Barak, J. D., and Schroeder, B. K. 2012. Interrelationships of food safety and plant pathology: The life cycle of human pathogens on plants. Annu. Rev. Phytopathol. 50:241-266. doi:10.1146/annurev-phyto-081211-172936

10. Barton Behravesh, C., Mody, R. K., Jungk, J., Gaul, L., Redd, J. T., Chen, S., Cosgrove, S., Hedican, E., Sweat, D., Chavez-Hauser, L., Snow, S. L., Hanson, H., Nguyen, T. A., Sodha, S. V., Boore, A. L., Russo, E., Mikoleit, M., Theobald, L., Gerner-Smidt, P., Hoekstra, R. M., Angulo, F. J., Swerdlow, D. L., Tauxe, R. V., Griffin, P. M., Williams, I. T., and Salmonella Saintpaul Outbreak Investigation, T. 2011. 2008 outbreak of Salmonella Saintpaul infections associated with raw produce. N. Engl. J. Med. 364(10):918-927. doi:10.1056/NEJMoa1005741

11. Barton-Behravesh, C., Williams, I. T., and Tauxe, R. V. 2012. Emerging foodborne pathogens and problems: Expanding prevention efforts before slaughter or harvest. Pages 307-331 in: Improving Food Safety Through a One Health Approach; Workshop Summary. E. Choffnes, D. Relman, L. Olsen, R. Hutton, and A. Mack, eds. The National Academies Press, Washington, DC.

12. Berger, C. N., Sodha, S. V., Shaw, R. K., Griffin, P. M., Pink, D., Hand, P., and Frankel, G. 2010. Fresh fruit and vegetables as vehicles for the transmission of human pathogens. Environ. Microbiol. 12(9):2385-2397. doi:10.1111/j.1462-2920.2010.02297.x

13. Beuchat, L. 1998. Surface decontamination of fruits and vegetables eaten raw: A review. http://www.who.int/foodsafety/publications/fs_management/ surfac_decon/en/. Accessed Oct 20, 2003. World Health Organization, Food Saftety Unit, Geneva.
14. Bowen, A., Fry, A., Richards, G., and Beuchat, L. 2006. Infections associated with cantaloupe consumption: A public health concern. Epidemiol. Infect. 134(4):675-685. doi:10.1017/S0950268805005480

15. Brandl, M. T. 2006. Fitness of human enteric pathogens on plants and implications for food safety. Annu. Rev. Phytopathol. 44:367-392. doi: 10.1146/annurev.phyto.44.070505.143359

16. Brandl, M. T. 2008. Plant lesions promote the rapid multipication of Escherichia coli $\mathrm{O} 157: \mathrm{H} 7$ on postharvest lettuce. Appl. Environ. Microbiol. 74:5285-5289.

17. CDC. 2011. Multistate outbreak of Listeriosis linked to whole cantaloupes from Jensen Farms, Colorado. http://www.cdc.gov/listeria/outbreaks/ cantaloupes-jensen-farms/index.html

18. Chisholm, S. T., Coaker, G., Day, B., and Staskawicz, B. J. 2006. Hostmicrobe interactions: Shaping the evolution of the plant immune response. Cell 124:803-914.

19. Crepin, A., Beury-Cirou, A., Barbey, C., Farmer, C., Helias, V., Burini, J. F., Faure, D., and Latour, X. 2012. N-Acyl Homoserine lactones in diverse Pectobacterium and Dickeya plant pathogens: Diversity, abundance, and involvement in virulence. Sensors 12:3484-3497.

20. Danhorn, T., and Fuqua, C. 2007. Biofilm formation by plant-associated bacteria. Annu. Rev. Microbiol. 61:401-422. doi:10.1146/annurev.micro. 61.080706 .093316

21. Deering, A. J., Mauer, L. J., and Pruitt, R. E. 2012. Internalization of E. coli O157:H7 and Salmonella spp. in plants: A review. Food Res. Int. 45(2):567-575. doi:10.1016/j.foodres.2011.06.058

22. Dong, Y. H., Wang, L. H., Xu, J. L., Zhang, H. B., Zhang, X. F., and Zhang, L. H. 2001. Quenching quorum-sensing-dependent bacterial infection by an N-acyl homoserine lactonase. Nature 411(6839):813-817.

23. Doyle, M. P., and Erickson, M. C. 2012. Opportunities for mitigating pathogen contamination during on-farm food production. Int. J. Food Microbiol. 152:54-74.

24. Erickson, M. 2012. Internalization of fresh produce by foodborne pathogens. Annu. Rev. Food Sci.Technol. 3:283-310.

25. FDA. 2013. Standards for growing, harvesting, packing and holding of produce for human consumption. http://www.ofr.gov/OFRUpload/ OFRData/2013-00123_PI.pdf

26. Fett, W. F. 2000. Naturally occurring biofilms on alfalfa and other types of sprouts. J. Food Prot. 63:625-632.

27. Fett, W. F., and Cooke, P. H. 2005. Native microbial aggregates on alfalfa, clover and mung bean sprout cotyledons for thickness as determined by confocal scanning laser microscopy. Food Microbiol. 22:253-259.

28. Gautam, D., Payton, M., Fletcher, J., and Ma, L. 2012. Surface survival and internalization of Salmonella through natural cracks on developing cantaloupe fruit, alone or in the presence of the plant pathogen Erwinia tracheiphila. International Association of Food Protection Annual Meeting, Providence, RI.

29. Gimenez-Ibanez, S., and Rathjen, J. P. 2010. The case for the defense: Plants versus Pseudomonas syringae. Microbes Infect. 12:428-437.

30. Gu, G. Y., Hu, J. H., Cevallos-Cevallos, J. M., Richardson, S. M., Bartz, J. A., and van Bruggen, A. H. C. 2011. Internal colonization of Salmonella enterica serovar Typhimurium in tomato plants. Plos One 6(11). doi:10.1371/journal.pone.0027340

31. Guidance for Industry: Guide to Minimize Microbial Food Safety Hazards for Fresh Fruits and Vegetables. 1998. FDA Center for Food Safety and Applied Nutrition, Washington, DC. http://www.fda.gov/Food/ GuidanceComplianceRegulatoryInformation/GuidanceDocuments/Produce andPlanProducts/ucm064574.htm

32. Guo, X. 2001. Survival of Salmonellae on and in tomato plants from the time of inoculation at flowering and early stages of fruit development through fruit ripening. Appl. Environ. Microbiol. 67:4760-4764.

33. Gupta, S. K., Nalluswami, K., Snider, C., Perch, M., Balasegaram, M., Burmeister, D., Lockett, J., Sandt, C., Hoekstra, R. M., and Montgomery, S. 2007. Outbreak of Salmonella Braenderup infections associated with Roma tomatoes, northeastern United States, 2004: A useful method for subtyping exposures in field investigations. Epidemiol. Infect. 135(7): 1165-1173. doi:10.1017/S0950268807007911

34. Hancock, D., Besser, T., and Rice, D. 1998. Ecology of Escherichia coli O157:H7 in cattle and impact of management practices. Pages 85-91 in: Escherichia coli O157:H7 and Other Shiga Toxin-Producing E. coli Strains. J. Kaper and A. O'Brien, eds. ASM Press, Washington, DC.

35. Hao, L. Y., Willis, D. K., Andrews-Polymenis, H., McClelland, M., and Barak, J. D. 2012. Requirement of siderophore biosynthesis for plant colonization by Salmonella enterica. Appl. Environ. Microbiol. 78(13): 4561-4570. doi:10.1128/AEM.07867-11

36. He, J., Baldini, R. L., Déziel, E., Saucier, M., Zhang, Q., Liberati, N. T., Lee, D., Urbach, J., Goodman, H. M., and Rahme, L. G. 2004. The broad host range pathogen Pseudomonas aeruginosa strain PA14 carries two pathogenicity islands harboring plant and animal virulence genes. Proc. Natl. Acad. Sci. U.S.A. 101(8):2530-2535. doi:10.1073/pnas.0304622101 
37. Heuer, H., Schmitt, H., and Smalla, K. 2011. Antibiotic resistance gene spread due to manure application on agricultural fields. Curr. Opin. Microbiol. 14(3):236-243. doi:10.1016/j.mib.2011.04.009

38. Hilborn, E. D., Mermin, J. H., Mshar, P. A., Hadler, J. L., Voetsch, A., Wojtkunski, C., Swartz, M., Mshar, R., Lambert-Fair, M. A., Farrar, J. A., Glynn, M. K., and Slutsker, L. 1999. A multistate outbreak of Escherichia coli $\mathrm{O} 157: \mathrm{H} 7$ infections associated with consumption of mesclun lettuce. Arch. Intern. Med. 159(15):1758-1764.

39. Ingle, R. A., Carstens, M., and Denby, K. J. 2006. PAMP recognition and the plant-pathogen arms race. BioEssays 28:880-889.

40. Iniguez, A. L., Dong, Y. M., Carter, H. D., Ahmer, B. M. M., Stone, J. M., and Triplett, E. W. 2005. Regulation of enteric endophytic bacterial colonization by plant defenses. Mol. Plant-Microbe Interact. 18:169-178. doi:10.1094/mpmi-18-0169

41. Islam, M., Doyle, M. P., Phatak, S. C., Millner, P., and Jiang, X. P. 2004. Persistence of enterohemorrhagic Escherichia coli O157:H7 in soil and on leaf lettuce and parsley grown in fields treated with contaminated manure composts or irrigation water. J. Food Prot. 67(7):1365-1370.

42. Islam, M., Morgan, J., Doyle, M. P., Phatak, S. C., Millner, P., and Jiang, X. P. 2004. Fate of Salmonella enterica serovar Typhimurium on carrots and radishes grown in fields treated with contaminated manure composts or irrigation water. Appl. Environ. Microbiol. 70(4):2497-2502. doi: 10.1128/Aem.70.4.2497-2502.2004

43. Itoh, Y., Sugita-Konishi, Y., Kasuga, F., Iwaki, M., Hara-Kudo, Y., Saito, N., Noguchi, Y., Konuma, H., and Kumagai, S. 1998. Enterohemorrhagic Escherichia coli O157:H7 present in radish sprouts. Appl. Environ. Microbiol. 64(4):1532-1535.

44. Jaquette, C. B., Beuchat, L. R., and Mahon, B. E. 1996. Efficacy of chlorine and heat treatment in killing Salmonella stanley inoculated onto alfalfa seeds and growth and survival of the pathogen during sprouting and storage. Appl. Environ. Microbiol. 62(7):2212-2215.

45. Kisluk, G., and Yaron, S. 2012. Presence and persistence of Salmonella enterica serotype Typhimurium in the phyllosphere and rhizosphere of spray-irrigated parsley. Appl. Environ. Microbiol. 78(11):4030-4036. doi:10.1128/aem.00087-12

46. Klerks, M. M., Franz, E., van Gent-Pelzer, M., Zijlstra, C., and van Bruggen, A. H. C. 2007. Differential interaction of Salmonella enterica serovars with lettuce cultivars and plant-microbe factors influencing the colonization efficiency. ISME J. 1(7):620-631. doi:10.1038/ismej.2007.82

47. Kroupitski, Y., Golberg, D., Belausov, E., Pinto, R., Swartzberg, D., Granot, D., and Sela, S. 2009. Internalization of Salmonella enterica in leaves is induced by light and involves chemotaxis and penetration through open stomata. Appl. Environ. Microbiol. 75(19):6076-6086. doi:10.1128/AEM.01084-09

48. Kroupitski, Y., Pinto, R., Brandl, M. T., Belausov, E., and Sela, S. 2009. Interactions of Salmonella enterica with lettuce leaves. J. Appl. Microbiol. 106(6):1876-1885. doi:10.1111/j.1365-2672.2009.04152.x

49. Lapidot, A., Romling, U., and Yaron, S. 2006. Biofilm formation and the survival of Salmonella Typhimurium on parsley. Int. J. Food Microbiol. 109(3):229-233. doi:10.1016/j.ijfoodmicro.2006.01.012

50. Lapidot, A., and Yaron, S. 2009. Transfer of Salmonella enterica serovar Typhimurium from contaminated irrigation water to parsley is dependent on curli and cellulose, the biofilm matrix components. J. Food Prot. 72(3):618-623

51. Lindow, S. E., and Brandl, M. T. 2003. Microbiology of the phyllosphere. Appl. Environ. Microbiol. 69(4):1875-1883.

52. Lugtenberg, B. J., Chin, A. W. T. F., and Bloemberg, G. V. 2002. Microbe-plant interactions: Principles and mechanisms. Antonie Van Leeuwenhoek 81(1-4):373-383.

53. Lynch, M. F., and Tauxe, R. V. 2009. Salmonellosis: Nontyphoidal. Chapter 32 in: Bacterial Infections of Humans, 4th ed. P. S. Brachman and E. Abrutyn, eds. Springer, New York.

54. Lynch, M. F., Tauxe, R. V., and Hedberg, C. W. 2009. The growing burden of foodborne outbreaks due to contaminated fresh produce: Risks and opportunities. Epidemiol. Infect. 137(3):307-315. doi:10.1017/ S0950268808001969

55. Macovei, L., Miles, B., and Zurek, L. 2008. The potential of house flies to contaminate ready-to-eat food with antibiotic resistant enterococci. J. Food Prot. 71:432-439.

56. McManus, P. S., Stockwell, V. O., Sundin, G. W., and Jones, A. L. 2002. Antibiotic use in plant agriculture. Annu. Rev. Phytopathol. 40:443-465. doi:10.1146/annurev.phyto.40.120301.093927

57. Melotto, M., Underwood, W., and He, S. Y. 2008. Role of stomata in plant innate immunity and foliar bacterial diseases. Annu. Rev. Phytopathol. 46:101-122.

58. Melotto, M., Underwood, W., Nomura, K., and He, S. Y. 2006. Plant stomata function in innate immunity against bacterial infection. Cell 126: 969-980.

59. Mitra, R., Cuesta-Alonso, E., Wayadande, A., Talley, J., Gilliland, S., and
Fletcher, J. 2009. Effect of route of introduction and host cultivar on the colonization, internalization, and movement of the human pathogen Escherichia coli O157:H7 in spinach. J. Food Prot. 72:1521-1530.

60. Mody, R. K., Greene, S. A., Gaul, L., Sever, A., Pichette, S., Zambrana, I., Dang, T., Gass, A., Wood, R., Herman, K., Cantwell, L. B., Falkenhorst, G., Wannemuehler, K., Hoekstra, R. M., McCullum, I., Cone, A., Franklin, L., Austin, J., Delea, K., Behravesh, C. B., Sodha, S. V., Yee, J. C., Emanuel, B., Al-Khaldi, S. F., Jefferson, V., Williams, I. T., Griffin, P. M., and Swerdlow, D. L. 2011. National outbreak of Salmonella serotype saintpaul infections: Importance of Texas restaurant investigations in implicating jalapeno peppers. PLoS One 6(2):e16579. doi:10.1371/ journal.pone.0016579

61. Morris, C. E., and Monier, J. M. 2003. The ecological significance of biofilm formation by plant-associated bacteria. Annu. Rev. Phytopathol. 41:429-453. doi:10.1146/annurev.phyto.41.022103.134521

62. Olaimat, A. N., and Holley, R. A. 2012. Factors influencing the microbial safety of fresh produce: A review. Food Microbiol. 32(1):1-19. doi:10.1016/j.fm.2012.04.016

63. Osterholm, M. T., Ostrowsky, J., Farrar, J. A., Gravani, R. B., Tauxe, R. V., Buchanan, R. L., and Hedberg, C. W. 2009. A novel approach to enhance food safety: Industry-academia-government partnership for applied research. J. Food Prot. 72:1509-1512.

64. Penteado, A. L., Eblen, B. S., and Miller, A. J. 2004. Evidence of Salmonella internalization into fresh mangos during simulated postharvest insect disinfestation procedures. J. Food Prot. 67:181-184.

65. Quilliam, R. S., Williams, A. P., and Jones, D. L. 2012. Lettuce cultivar mediates both phyllosphere and rhizosphere activity of Escherichia coli O157:H7. Plos One 7(3). doi:10.1371/journal.pone.0033842

66. Raymundo, A. K., and Ries, S. M. 1980. Chemotaxis of Erwinia amylovora. Phytopathology 70:1066-1069.

67. Riedel, K., Hentzer, M., Geisenberger, O., Huber, B., Steidle, A., Wu, H., Hoiby, N., Givskov, M., Molin, S., and Eberl, L. 2001. N-Acylhomoserine-lactone-mediated communication between Pseudomonas aeruginosa and Burkholderia cepacia in mixed biofilms. Microbiology 147(Pt 12):3249-3262.

68. Ritchie, D. F. 2000. Bacterial spot of pepper and tomato. The Plant Health Instructor doi:10.1094/PHI-I-2000-1027-01

69. Roper, M. C. 2011. Pantoea stewartii subsp. stewartii: Lessons learned from a xylem-dwelling pathogen of sweet corn. Mol. Plant Pathol. 12(7):628-637. doi:10.1111/j.1364-3703.2010.00698.x

70. Rosenblueth, M., and Martinez-Romero, E. 2006. Bacterial endophytes and their interactions with hosts. Mol. Plant-Microbe Interact. 19:827837. doi:10.1094/Mpmi-19-0827

71. Rushing, J. W., Angulo, F. J., Beuchat, L. R. 1996. Implementation of a HACCP program in a commercial fresh-market tomato packinghouse: A model for the industry. Dairy Food Environ. Sanit. 16:549-553.

72. Saldaña, Z., Sánchez, E., Xicohtencatl-Cortes, J., Puente, J. L., and Giron, J. A. 2011. Surface structures involved in plant stomata and leaf colonization by Shiga-toxigenic Escherichia coli O157:H7. Front. Microbiol. doi:10.3389/fmicb.2011.00119

73. Schikora, A., Garcia, A. V., and Hirt, H. 2012. Plants as alternative hosts for Salmonella. Trends Plant Sci. 17(5):245-249. doi:10.1016/j.tplants. 2012.03.007

74. Schikora, A., Virlogeux-Payant, I., Bueso, E., Garcia, A. V., Nilau, T., Charrier, A., Pelletier, S., Menanteau, P., Baccarini, M., Velge, P., and Hirt, H. 2011. Conservation of Salmonella infection mechanisms in plants and animals. Plos One 6(9). doi:10.1371/journal.pone.0024112

75. Shirron, N., and Yaron, S. 2011. Active suppression of early immune response in tobacco by the human pathogen Salmonella Typhimurium. PLoS One 6(4):e18855. doi:10.1371/journal.pone.0018855

76. Silo-Suh, L., Suh, S.-J., Sokol, P. A., and Ohman, D. E. 2002. A simple alfalfa seedling infection model for Pseudomonas aeruginosa strains associated with cystic fibrosis shows AlgT (sigma-22) and RhlR contribute to pathogenesis. Proc. Natl. Acad. Sci. U.S.A. 99(24):1569915704. doi:10.1073/pnas.242343999

77. Sivapalasingam, S., Friedman, C. R., Cohen, L., and Tauxe, R. V. 2004. Fresh produce: a growing cause of outbreaks of foodborne illness in the United States, 1973 through 1997. J. Food Prot. 67(10):2342-2353.

78. Smith, J. L., Fratamico, P. M., and Yan, X. 2011. Eavesdropping by bacteria: The role of SdiA in Escherichia coli and Salmonella enterica serovar Typhimurium quorum sensing. Foodborne Pathog. Dis. 8(2):169178. doi:10.1089/fpd.2010.0651

79. Staskawicz, B. J., Mudgett, M. B., Dangl, J. L., and Galan, J. E. 2001. Common and contrasting themes of plant and animal diseases. Science 292(5525):2285-2289. doi:10.1126/science.1062013

80. Talley, J. L., Wayadande, A. C., Wasala, L. P., Gerry, A. C., Fletcher, J., DeSilva, U., and Gilliland, S. E. 2009. Association of Escherichia coli O157:H7 with filth flies (Muscidae and Calliphoridae) captured in leafy greens fields and experimental transmission of E. coli $\mathrm{O} 157: \mathrm{H} 7$ to spinach 
leaves by house flies (Diptera: Muscidae). J. Food Prot. 72:1547-1552.

81. Telford, J. L., Barocchi, M. A., Margarit, I., Rappuoli, R., and Grandi, G. 2006. Gram positive pathogens. Nat. Rev. Microbiol. 4:509-519.

82. Teplitski, M., Barak, J. D., and Schneider, K. R. 2009. Human enteric pathogens in produce: Un-answered ecological questions with direct implications for food safety. Curr. Opin. Plant Biotechnol. 20:166-171. doi:10.1016/j.copbio.2009.03.002

83. Teplitski, M., Noel, J. T., Alagely, A., and Danyluk, M. D. 2012. Functional genomics studies shed light on the nutrition and gene expression of non-typhoidal Salmonella and enterovirulent E. coli in produce. Food Res. Int. 45(2):576-586. doi:10.1016/j.foodres.2011.06.020

84. Vidaver, A. K., Tolin, S., and Lambrecht, P. 2006. Laboratory, growth chamber and greenhouse microbial safety: Plant pathogens and plant associated microorganisms of significance to human health. In: Biological Safety: Principles and Practices. D. O. Fleming and D. L. Hunt, eds. ASM Press, Washington, DC.

85. Wagenaar, J. 2008. Poultry colonization with Campylobacter and its control at the primary production level. Chapter 37 in: Campylobacter. C. S. I. N. Nachamkin, C. M. Scymanski, and M. Blaser, eds. ASM Press, Washington, DC

86. Wells, J. M., and Butterfield, J. E. 1997. Salmonella contamination associated with bacterial soft rot of fresh fruits and vegetables in the marketplace. Plant Dis. 81:867-872.

87. Wendel, A. M., Johnson, D. H., Sharapov, U., Grant, J., Archer, J. R., Monson, T., Koschmann, C., and Davis, J. P. 2009. Multistate outbreak of Escherichia coli $0157: \mathrm{H} 7$ infection associated with consumption of packaged spinach, August-September 2006: The Wisconsin investigation. Clin. Infect. Dis. 48(8):1079-1086. doi:10.1086/597399

88. Wheeler, C., Vogt, T. M., Armstrong, G. L., Vaughan, G., Weltman, A., Nainan, O. V., Dato, V., Xia, G., Waller, K., Amon, J., Lee, T. M., Highbaugh-Battle, A., Hembree, C., Evenson, S., Ruta, M. A., Williams, I. T., Fiore, A. E., and Bell, B. P. 2005. An outbreak of hepatitis A associated with green onions. New Engl. J. Med. 353:890-897. doi:10.1056/ NEJMoa050855

89. Winfield, M. D., and Groisman, E. A. 2003. Role of nonhost environments in the lifestyles of Salmonella and Escherichia coli. Appl. Environ. Microbiol. 69(7):3687-3694.

90. You, Y., Rankin, S. C., Aceto, H. W., Benson, C. E., Toth, J. D., and Dou, Z. 2006. Survival of Salmonella enterica serovar Newport in manure and manure-amended soils. Appl. Environ. Microbiol. 72(9):5777-5783. doi:10.1128/AEM.00791-06

91. Zeng, W., Melotto, M., and He, S. Y. 2010. Plant stomata: A checkpoint of host immunity and pathogen virulence. Curr. Opin. Biotechnol. 21:599613. 